\title{
A New Six-Parameter Model Based on Chebyshev Polynomials for Solar Cells
}

\author{
Shu-xian Lun, ${ }^{1}$ Jing-shu Sang, ${ }^{2}$ and Ting-ting Guo ${ }^{2}$ \\ ${ }^{1}$ College of New Energy, Bohai University, Jinzhou 121013, China \\ ${ }^{2}$ School of Mathematics and Physics, Bohai University, Jinzhou 121013, China \\ Correspondence should be addressed to Shu-xian Lun; jzlunzi@163.com
}

Received 29 December 2014; Accepted 2 April 2015

Academic Editor: Georgios Veronis

Copyright (c) 2015 Shu-xian Lun et al. This is an open access article distributed under the Creative Commons Attribution License, which permits unrestricted use, distribution, and reproduction in any medium, provided the original work is properly cited.

\begin{abstract}
This paper presents a new current-voltage $(I-V)$ model for solar cells. It has been proved that series resistance of a solar cell is related to temperature. However, the existing five-parameter model ignores the temperature dependence of series resistance and then only accurately predicts the performance of monocrystalline silicon solar cells. Therefore, this paper uses Chebyshev polynomials to describe the relationship between series resistance and temperature. This makes a new parameter called temperature coefficient for series resistance introduced into the single-diode model. Then, a new six-parameter model for solar cells is established in this paper. This new model can improve the accuracy of the traditional single-diode model and reflect the temperature dependence of series resistance. To validate the accuracy of the six-parameter model in this paper, five kinds of silicon solar cells with different technology types, that is, monocrystalline silicon, polycrystalline silicon, thin film silicon, and tripe-junction amorphous silicon, are tested at different irradiance and temperature conditions. Experiment results show that the six-parameter model proposed in this paper is an $I-V$ model with moderate computational complexity and high precision.
\end{abstract}

\section{Introduction}

Photovoltaic (PV) power generation system directly converts solar energy into electrical energy by using PV arrays. To obtain higher energy efficiency, PV power generation systems need to establish their simulation models to get optimized parameters. $\mathrm{PV}$ power generation system is mainly composed of PV arrays, controller [1-3], and inverter [4-6]. PV arrays, the core devices of PV power generation system, usually consist of solar cells in series and/or in parallel. There are two kinds of popular simulation models for solar cells, that is, the single-diode model and the double-diode model [710]. Because of having fewer parameters, the single-diode model is simpler than the double-diode model. This makes the single-diode model widely used. Some efforts have been made to improve the accuracy of the single-diode model. According to the number of parameters, there are mainly three kinds of models, that is, the four-parameter model, the five-parameter model, and the seven-parameter model.

The four-parameter model in [11] includes ideality factor, diode reverse saturation current, light-generated current, series resistance. The four-parameter model has the fewest cell parameters, and then its expression is the simplest. However, the predicted accuracy of the four-parameter model is very limited. And the four-parameter model is validated only for monocrystalline silicon modules. On the basis of the four-parameter model, the five-parameter models are obtained by introducing shunt resistance [11-21]. The fiveparameter models are more precise than the four-parameter model in [11]. Compromising the number of parameters and the approximate accuracy, the five-parameter models are the most commonly used. The five-parameter models proposed in [11, 19-21] utilize the reciprocals of the slopes at the open-circuit point and short-circuit point to calculate the cell parameters. The two slope values are not usually provided by the manufacturers' datasheet. And they can be obtained by using enough data pairs of experimental $I-V$ characteristic under the certain condition. This makes it very complicated to obtain the slope values. Therefore, these five-parameter models actually have seven parameters rather than five parameters. The five-parameter model in [12] does not utilize the above-mentioned two slope parameters 


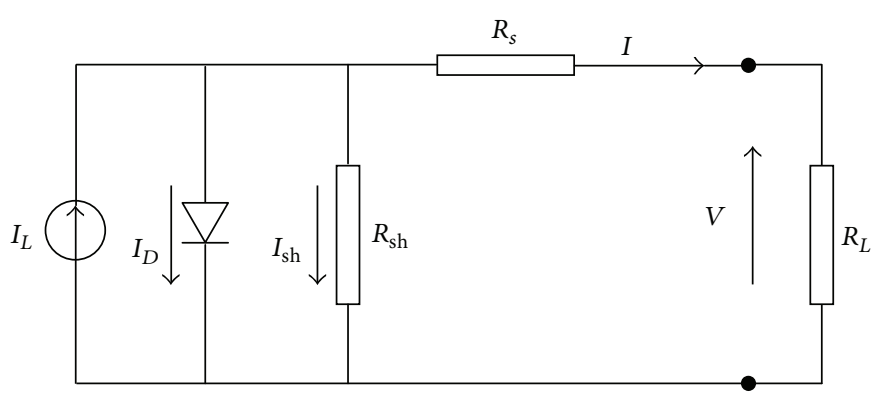

Figure 1: Single diode model.

and can accurately predict the performance of monocrystalline and polycrystalline silicon modules. However, the fiveparameter model in [12] exists large modeling errors for amorphous silicon solar cells. This may be due to the facts that series resistance in [12] is assumed to be a constant and the temperature dependence of series resistance is ignored. Here, temperature refers to the temperature of solar cells. The seven-parameter models proposed in $[13,22]$ add two additional parameters on the basis of the five-parameter model. For example, in [13], the two additional parameters are temperature coefficient for series resistance and the diode reverse saturation current radiation dependence, respectively. Temperature coefficient for series resistance describes the temperature dependence of series resistance. The value of series resistance changes exponentially with the cell temperature. The diode reverse saturation current radiation dependence describes the influence of irradiance on diode reverse saturation current, which is obtained by using the current and the voltage at maximum power point under the irradiance of $200 \mathrm{~W} / \mathrm{m}^{2}$ and the temperature of $25^{\circ} \mathrm{C}$. The extraction process for this parameter is very complicated. Although the seven-parameter model in [13] provides a more accurate $I-V$ characteristic model, it is not widely used because of the complexity of parameter extraction. Therefore, we propose a new six-parameter model.

In this paper, Chebyshev polynomials are developed to describe the relationship between series resistance and temperature. This makes a new parameter called temperature coefficient for series resistance introduced into the singlediode model. Therefore, the single-diode model has six cell parameters in this paper, that is, ideality factor, lightgenerated current, diode reverse saturation current, series resistance, shunt resistance, and temperature coefficient for series resistance. The new six-parameter model provides a simpler and more reasonable expression for series resistance and accurately predicts $I-V$ characteristic for silicon solar cells. Five kinds of silicon solar cells with four different technology types, that is, monocrystalline silicon, polycrystalline silicon, thin film silicon and triple-junction amorphous silicon, are tested to validate the six-parameter model in this paper.

\section{The Single-Diode Model of Solar Cells}

A solar cell is essentially a very large area $p-n$ junction diode. Under illumination, a single-diode model of a solar cell can be described by an equivalent circuit, shown in Figure 1. The $I-V$ equation of a single-diode model is shown as follows:

$$
I=I_{L}-I_{o}\left[\exp \left(\frac{V+I R_{s}}{a}\right)-1\right]-\frac{V+I R_{s}}{R_{\mathrm{sh}}},
$$

where $I_{L}(\mathrm{~A})$ is light-generated current, $I_{o}(\mathrm{~A})$ is diode reverse saturation current, $R_{\mathrm{sh}}(\Omega)$ is shunt resistance, and $R_{s}(\Omega)$ is series resistance, $a$ is ideality factor which is defined as follows:

$$
a=N_{s} n_{I} V_{t}
$$

where $N_{s}$ is the number of solar cells in series in a PV module, $n_{I}$ is diode ideality factor, and $V_{t}$ is thermal voltage which is defined as follows:

$$
V_{t}=\frac{k T}{q}
$$

where $k$ is Boltzmann's constant $(1.38066 E-23 \mathrm{~J} / \mathrm{K}), T(\mathrm{~K})$ is cell temperature, and $q$ is electron charge $(1.60218 E-19 \mathrm{C})$.

\section{Chebyshev Polynomials Are Used to Model Series Resistance in the Six-Parameter Model}

Temperature dependence of series resistance has been quantitatively analyzed and various expressions are obtained $[18,21,23-27]$. Most of the expressions are nonlinear and implicit formulations about temperature. In $[18,21,24]$, the relationship between series resistance and temperature is expressed as the exponential function of temperature. In [25], series resistance is literally expressed as the linear function of temperature. In fact, the expression also contains other electrical parameters at the same time, such as the short-circuit current and the voltage and the current at maximum power point, which are closely related to temperature. Therefore, the expression of series resistance in [25] is actually complex nonlinear. In addition, $[13,27]$ have given explicit representation of series resistance about temperature. Reference [27] has proved that series resistance of a solar cell belongs to positive temperature coefficient type. However, some of the series resistance of solar cells monotonically increases with the increase of temperature [23], but some of the series resistance of solar cells monotonically decreases with the increase of temperature $[28,29]$. Therefore, for different kinds of solar 
cells, the expression in [27] for temperature dependence of series resistance is limited. As is known, the expression of $I-V$ characteristic is a transcendental equation and series resistance is an exponential function of temperature. When series resistance with the exponential function is substituted into $I-V$ characteristic model, the processes of $I-V$ characteristic modeling and parameter extraction will become complex and have computational burden. Therefore, in this paper, we follow the relationship between series resistance and temperature in [13] to develop a new expression of series resistance about temperature. Chebyshev polynomials are used to describe temperature dependence of series resistance. It is worth mentioning that the new expression of series resistance about temperature is an explicit form in this paper.

\subsection{Chebyshev Polynomials Is Used to Model Series Resistance.} In this paper, we assume the range of temperature $T$ is from $233 \mathrm{~K}$ to $353 \mathrm{~K}$ and the magnitude order of $\delta$ is $10^{-3}$. Here, $\delta$ denotes temperature coefficient for series resistance. To satisfy the need of accuracy and simplification, we select cubic Chebyshev polynomials $[30,31]$ to establish the expression for temperature dependence of series resistance. The remainder of this cubic Chevbyshev polynomials is shown as follows in this section.

Since the magnitude order of $\delta$ is $10^{-3}$, we have

$$
|\delta| \in\left[1 \times 10^{-3}, 9 \times 10^{-3}\right] .
$$

Let

$$
\Delta_{T}=\delta\left(T-T_{\text {ref }}\right),
$$

where $T_{\text {ref }}$ denotes the temperature of $25^{\circ} \mathrm{C}$ at Standard Reference Condition (the irradiance is $1000 \mathrm{~W} / \mathrm{m}^{2}$, the temperature is $298 \mathrm{~K}$, and air mass is 1.5, SRC). Then, we have $\Delta_{T} \in[-0.585,0.495]$. Since $T-T_{\text {ref }} \in[-65,55]$, the following formula holds:

$$
\left|M_{n}\right|=\max _{-65 \delta \leq x \leq 55 \delta}\left\{\left|e^{\Delta_{T}}\right|\right\}=e^{55 \delta} \approx 1 .
$$

According to (6), we have

$$
\left|R_{3}(x)\right|=\frac{(120 \delta)^{3}\left|M_{n}\right|}{2^{7} \times 3 !}=\frac{(120 \delta)^{3} e^{55 \delta}}{2^{7} \times 3 !} \approx \frac{(120 \delta)^{3}}{2^{7} \times 3 !} .
$$

Substituting (4) into (7), we can obtain $\left|R_{3}(x)\right| \in[6.75 \times$ $\left.10^{-8}, 4.43 \times 10^{-4}\right]$.

Now, we use cubic Chebyshev polynomials $[30,31]$ to describe the expression for temperature dependence of series resistance as follows:

$$
R_{s}=R_{s, \text { ref }}\left(W_{3} \Delta_{T}^{3}-W_{2} \Delta_{T}^{2}+W_{1} \Delta_{T}-W_{0}\right),
$$

where $R_{s}$ is the series resistance, $R_{s, \text { ref }}$ is the series resistance at SRC, $W_{3}=\sum_{i=1} A_{i}, W_{2}=\sum_{i=1}\left(A_{i} \sum_{j=1} x_{j}\right), W_{1}=$ $\sum_{j \neq i, k \neq j \neq i}^{n \neq k \neq j \neq i} A_{i}\left[\left(x_{j}+x_{k}\right) x_{n}+x_{j} x_{k}\right], W_{0}=\sum_{i=1} A_{i}\left(\prod_{j=1}^{j \neq i} x_{j}\right)$, $(i, j, k, n=1,2,3,4)$, and $A_{i}$ is defined as follows:

$$
A_{i}=\frac{e^{x_{i}}}{\prod_{j=2, j \neq i}^{4}\left(x_{i}-x_{j}\right)},
$$

where $x_{i}$ is defined as follows:

$$
x_{i}=-5 \delta+60 \delta \cdot \cos \left(\frac{2 i-1}{8} \pi\right), \quad(i=1,2,3,4) .
$$

3.2. Six-Parameter Model. Manufacturers usually provide some data at SRC, such as short-circuit current $I_{\mathrm{sc}}$, opencircuit voltage $V_{\mathrm{oc}}$, current and voltage at maximum power point, $I_{\mathrm{mp}}, V_{\mathrm{mp}}$, and their temperature coefficient $\alpha_{\mathrm{Isc}_{\mathrm{sc}}}, \beta_{V_{\mathrm{oc}}}$, $\alpha_{I_{\mathrm{mp}}}$, and $\beta_{V_{\mathrm{mp}}}$.

To obtain current corresponding to different voltage at various conditions, $a, I_{L}, I_{o}, R_{s}$, and $R_{\mathrm{sh}}$ must be known. Firstly, we calculate these parameters at SRC, that is, $a_{\text {ref }}, I_{L, \text { ref }}, I_{o, \text { ref }}, R_{s, \text { ref }}, R_{\text {sh,ref }}$. Here, the parameters with subscript "ref" denote the values at SRC. According to (8), we know that series resistance is related to the temperature coefficient for series resistance $\delta$. Therefore, $\delta$ also needs to be calculated. Thus, we need six pieces of independent information to calculate the six parameters. In this paper, we make full use of the definitions of $I_{\mathrm{sc}}, V_{\mathrm{oc}}, I_{\mathrm{mp}}, V_{\mathrm{mp}}, \alpha_{I_{\mathrm{sc}}}$, $\beta_{V_{\mathrm{oc}}}, \alpha_{I_{\mathrm{mp}}}, \beta_{V_{\mathrm{mp}}}$, and manufacturers' data at SRC to obtain the above-mentioned six parameters.

According to the definition of short-circuit current at SRC, we have $I=I_{\text {sc,ref }}$ when $V=0$. Equation (1) is written as follows:

$$
I_{\mathrm{sc}, \text { ref }}=I_{L, \text { ref }}-I_{o, \text { ref }}\left[e^{I_{\mathrm{sc}, \mathrm{ref}} R_{\mathrm{s} \text {, ref }} / a_{\mathrm{ref}}}-1\right]-\frac{I_{\mathrm{sc}, \mathrm{ref}} R_{s, \mathrm{ref}}}{R_{\mathrm{sh}, \mathrm{ref}}} .
$$

According to the definition of open-circuit voltage at SRC, we have $V=V_{\text {oc,ref }}$ when $I=0$. Equation (1) is written as follows:

$$
0=I_{L, \text { ref }}-I_{o, \text { ref }}\left[e^{V_{\mathrm{oc}, \mathrm{ref}} / a_{\mathrm{ref}}}-1\right]-\frac{V_{\mathrm{oc}, \mathrm{ref}}}{R_{\mathrm{sh}, \mathrm{ref}}} .
$$

According to the definition of maximum-power point at SRC, we have $V=V_{\mathrm{mp} \text {,ref }}$ when $I=I_{\mathrm{mp}, \mathrm{ref}}$. Equation (1) is written as follows:

$$
\begin{aligned}
I_{\mathrm{mp}, \text { ref }}= & I_{L, \text { ref }}-I_{o, \text { ref }}\left[\frac{V_{\mathrm{mp}, \text { ref }}+I_{\mathrm{mp}, \text { ref }} R_{s, \text { ref }}}{a_{\text {ref }}}-1\right] \\
& -\frac{V_{\mathrm{mp}, \text { ref }}+I_{\mathrm{mp}, \text { ref }} R_{s, \text { ref }}}{R_{\mathrm{sh}, \text { ref }}} .
\end{aligned}
$$

At maximum-power point, the derivation of power is zero, we can obtain

$$
\begin{aligned}
0 & =I_{\mathrm{mp}, \mathrm{ref}}+V_{\mathrm{mp}, \mathrm{ref}} \\
& \cdot \frac{\left(-I_{o, \text { ref }} / a_{\mathrm{ref}}\right) e^{\left(V_{\mathrm{mp}, \mathrm{ref}}+I_{\mathrm{mp}, \mathrm{ref}} R_{\mathrm{s}, \mathrm{ref}}\right) / a_{\mathrm{ref}}}-1 / R_{\mathrm{sh}, \mathrm{ref}}}{1+\left(I_{o, \text { ref }} R_{s, \mathrm{ref}} / a_{\mathrm{ref}}\right) e^{\left(V_{\mathrm{mp}, \mathrm{ref}}+I_{\mathrm{mp}, \mathrm{ref}} R_{\mathrm{s}, \mathrm{ref}}\right) / a_{\mathrm{ref}}}+R_{s, \text { ref }} / R_{\mathrm{sh}, \mathrm{ref}}} .
\end{aligned}
$$

For now, we have four pieces of independent information with six unknown parameters. We need to add two pieces of information. $\beta_{V_{\mathrm{oc}}}$ and $\gamma_{P_{\mathrm{mp}}}$ (the temperature coefficient for maximum power) are used as the added information. It is worth mentioning that the units of $\beta_{V_{o c}}$ and $\gamma_{P_{\mathrm{mp}}}$ are $\mathrm{V} / \mathrm{K}$ and $1 / \mathrm{K}$, respectively. 
TABLE 1: Values of different types of solar cells provided by NIST and SNL.

\begin{tabular}{|c|c|c|c|c|c|}
\hline PV module specifications & SP-75 & SM-55 & MSX-64 & APX-90 & US-21 \\
\hline Material & Monocrystalline & Monocrystalline & Polycrystalline & Thin film & 3-jun amorphous \\
\hline$I_{\mathrm{sc}, \mathrm{ref}}(\mathrm{A})$ & 4.37 & 3.45 & 4.25 & 5.11 & 1.59 \\
\hline$V_{\text {oc,ref }}(\mathrm{V})$ & 42.93 & 21.7 & 41.5 & 29.61 & 23.8 \\
\hline$I_{\mathrm{mp}, \mathrm{ref}}(\mathrm{A})$ & 3.96 & 3.15 & 3.82 & 4.49 & 1.27 \\
\hline$V_{\text {mp,ref }}(\mathrm{V})$ & 33.68 & 17.4 & 32.94 & 23.17 & 16.5 \\
\hline$\alpha_{I_{\mathrm{sc}}}(\mathrm{A} / \mathrm{K})$ & 0.00175 & 0.0019 & 0.00238 & 0.00468 & 0.00135 \\
\hline$\beta_{V_{\mathrm{oc}}}(\mathrm{V} / \mathrm{K})$ & -0.15237 & -0.087 & -0.15280 & -0.12995 & -0.098 \\
\hline$\alpha_{I_{\mathrm{mp}}}(\mathrm{A} / \mathrm{K})$ & -0.00154 & -0.000254 & 0.00018 & 0.00160 & 0.0015 \\
\hline$\beta_{V_{\mathrm{mp}}}(\mathrm{V} / \mathrm{K})$ & -0.15358 & -0.089 & -0.15912 & -0.13039 & -0.052 \\
\hline$E_{g, \text { ref }}(\mathrm{eV})$ & 1.12 & 1.12 & 1.14 & 1.12 & 1.6 \\
\hline$N_{s}$ & 72 & 36 & 72 & 56 & 11 \\
\hline
\end{tabular}

The temperature coefficient for open-circuit voltage $\left(\beta_{V_{\mathrm{oc}}}\right)$ can be defined as follows:

$$
\beta_{V_{\mathrm{oc}}} \approx \frac{V_{\mathrm{oc}, \mathrm{ref}}-V_{\mathrm{oc}, T}}{T_{\mathrm{ref}}-T} .
$$

The temperature coefficient for maximum-power point $\left(\gamma_{P_{\mathrm{mp}}}\right)$ can be defined as follows:

$$
\gamma_{P_{\mathrm{mp}}} \approx \frac{P_{\mathrm{mp}, \mathrm{ref}}-P_{\mathrm{mp}, T}}{P_{\mathrm{mp}, \mathrm{ref}}\left(T_{\mathrm{ref}}-T\right)} .
$$

In (15) and (16), temperature $T$ can change from $288 \mathrm{~K}$ to $308 \mathrm{~K} . \beta_{V_{\mathrm{oc}}}$ can be given by manufacturers, $\gamma_{P_{\mathrm{mp}}}$ is also given by manufacturers or calculated by using the values of $\alpha_{I_{\mathrm{mp}}}$ and $\beta_{V_{\mathrm{mp}}}$. But $V_{\mathrm{oc}, T}$ and $P_{\mathrm{mp}, T}$ are unknown in (15) and (16). To compute $V_{\mathrm{oc}, T}$ and $P_{\mathrm{mp}, T}$, we have to obtain the values of $a$, $I_{L}, I_{o}$, and $R_{\mathrm{sh}}$ at any temperature and irradiance conditions. Therefore, (17) show the expressions of $a, I_{L}, I_{o}$, and $R_{\mathrm{sh}}$ at any temperature and irradiance conditions.

At any conditions, $a, I_{o}, I_{L}$, and $R_{\mathrm{sh}}$ can be expressed as follows [7]:

$$
\begin{aligned}
a & =a_{\text {ref }} \frac{T}{T_{\text {ref }}}, \\
I_{o} & =I_{o, \text { ref }}\left(\frac{T}{T_{\text {ref }}}\right)^{3} \\
& \cdot \exp \left[\frac{1.60207 \times 10^{-19}}{k}\left(\frac{E_{g, \text { ref }}}{T_{\text {ref }}}-\frac{E_{g, T}}{T}\right)\right], \\
I_{L} & =\frac{G}{G_{\text {ref }}}\left[I_{L, \text { ref }}+\alpha_{I_{\mathrm{sc}}}\left(T-T_{\text {ref }}\right)\right], \\
R_{\mathrm{sh}} & =R_{\text {sh,ref }} \frac{G_{\text {ref }}}{G},
\end{aligned}
$$

where $k$ is Boltzmann's constant and $E_{g}$ is the material band gap. $E_{g \text {,ref }}$ is the material band gap at SRC shown in Table 1, which depends on different technology types of solar cells. In addition, the value of $E_{g}$ at any conditions is shown as follows:

$$
E_{g}=E_{g, \text { ref }}\left[1-0.0002677\left(T-T_{\text {ref }}\right)\right] \text {. }
$$

Form (5) and (8), the expression of series resistance can be rewritten as follows:

$$
\begin{aligned}
R_{s} & =R_{s, \text { ref }}\left\{W_{3}\left[\delta\left(T-T_{\text {ref }}\right)\right]^{3}-W_{2}\left[\delta\left(T-T_{\text {ref }}\right)\right]^{2}\right. \\
& \left.+W_{1}\left[\delta\left(T-T_{\text {ref }}\right)\right]-W_{0}\right\} .
\end{aligned}
$$

According to the data provided by manufacturers at SRC, we can obtain $a_{\text {ref }}, I_{L, \text { ref }}, I_{o, \text { ref }}, R_{\text {sh,ref }}, R_{s, \text { ref }}$, and $\delta$ by using (11)-(16). Then, (17)-(19) are used to determine a, $I_{L}, I_{o}, R_{\mathrm{sh}}$, and $R_{s}$ of $I-V$ characteristics for different solar cells at any temperature and irradiance conditions. Once the five parameters are obtained at certain temperature and irradiance condition, we can easily obtain the current corresponding to different voltage according to (1). Therefore, (11)-(19) are called the six-parameter model. $V_{\mathrm{mp}}, I_{\mathrm{mp}}, V_{\mathrm{oc}}$, and $I_{\mathrm{sc}}$ at any conditions are significant and have practical application. However, (11)-(14) are special representation of (1) at SRC for three important points: $\left(V_{\mathrm{mp}}, I_{\mathrm{mp}}\right),\left(0, I_{\mathrm{sc}}\right)$, and $\left(V_{\mathrm{oc}}, 0\right)$. That is to say, (11)-(14) can directly obtain $V_{\mathrm{mp}}, I_{\mathrm{mp}}$, $V_{\mathrm{oc}}$, and $I_{\mathrm{sc}}$ at any conditions when subscript "ref" is deleted.

\section{Model Validation and Discussion}

In this section, we select five kinds of PV modules with four technology types to validate the six-parameter model proposed in this paper. They are Siemens SP75 and Siemens SM-55 (monocrystalline silicon), Solarex MSX-64 (polycrystalline silicon), Anstropower APX-90 (thin film silicon), and USSC US-21 (tripe-junction amorphous silicon), respectively. These five PV modules are composed of different number of solar cells in series, shown in Table 1 . The reference values of SP75, MSX-64, APX-90 are provided by NIST (Nation Institute of Standards and Technology). The reference values of US21, SM-55 are provided by SNL (Sandia National Laboratory), shown in Table 1. To analyse the accuracy of the six-parameter model proposed in this paper, the absolute 
TABLE 2: The parameter values of different models at SRC.

\begin{tabular}{|c|c|c|c|c|c|c|}
\hline & Parameters & SP-75 & SM-55 & MSX-64 & APX-90 & US-21 \\
\hline \multirow{6}{*}{$\begin{array}{l}\text { Six-parameter } \\
\text { model }\end{array}$} & $a_{\mathrm{ref}}$ & 1.76895 & 0.95447 & 1.71640 & 1.37500 & 0.76136 \\
\hline & $I_{L, \text { ref }}(\mathrm{A})$ & 4.39492 & 3.46140 & 4.27627 & 5.15344 & 1.69385 \\
\hline & $I_{o, \text { ref }}(\mathrm{A})$ & $1.200098 E-10$ & $4.432196 E-10$ & $1.262302 E-10$ & $2.092911 E-9$ & $3.467982 E-14$ \\
\hline & $R_{s, \text { ref }}(\Omega)$ & 1.03711 & 0.48750 & 0.91975 & 0.56864 & 4.01381 \\
\hline & $R_{\mathrm{sh}, \mathrm{ref}}(\Omega)$ & 181.86447 & 147.52754 & 148.79240 & 66.89309 & 61.45488 \\
\hline & $\delta$ & 0.0038193 & 0.0042272 & 0.0039503 & 0.0036350 & -0.0090814 \\
\hline \multirow{5}{*}{$\begin{array}{l}\text { Five-parameter } \\
\text { model in [14] }\end{array}$} & $a_{\text {ref }}$ & 1.76895 & 0.95447 & 1.71640 & 1.37500 & 0.76135 \\
\hline & $I_{L, \mathrm{ref}}(\mathrm{A})$ & 4.39492 & 3.46140 & 4.27627 & 5.15344 & 1.69385 \\
\hline & $I_{o, \text { ref }}(\mathrm{A})$ & $1.200098 E-10$ & $4.432190 E-10$ & $1.262314 E-10$ & $2.092908 E-9$ & $3.467660 E-14$ \\
\hline & $R_{s, \text { ref }}(\Omega)$ & 1.03711 & 0.48750 & 0.91974 & 0.56864 & 4.01382 \\
\hline & $R_{\mathrm{sh}, \mathrm{ref}}(\Omega)$ & 181.86449 & 147.52752 & 148.79407 & 66.89302 & 61.45483 \\
\hline \multirow{7}{*}{$\begin{array}{l}\text { Seven-parameter } \\
\text { model in [13] }\end{array}$} & $a_{\text {ref }}$ & 1.76895 & 0.95446 & 1.71640 & 1.37500 & 0.76136 \\
\hline & $I_{L, \mathrm{ref}}(\mathrm{A})$ & 4.39492 & 3.46140 & 4.27627 & 5.15344 & 1.69385 \\
\hline & $I_{o, \text { ref }}(\mathrm{A})$ & $1.200098 E-10$ & $4.431875 E-10$ & $1.262312 E-10$ & $2.092909 E-9$ & $3.467982 E-14$ \\
\hline & $R_{s, \text { ref }}(\Omega)$ & 1.03711 & 0.48750 & 0.91974 & 0.56864 & 4.01381 \\
\hline & $R_{\text {sh,ref }}(\Omega)$ & 181.86445 & 147.52677 & 148.79405 & 66.89309 & 61.45484 \\
\hline & $\delta$ & 0.0038200 & 0.0042278 & 0.0039510 & 0.0036360 & -0.0090720 \\
\hline & $m$ & $5.248 E-3$ & $-8.527 E-5$ & $5.040 E-6$ & $-1.602 E-6$ & $1.665 E-4$ \\
\hline
\end{tabular}

error (AE), the relative error ( $\mathrm{RE}$ ), and the root mean squared error (RMSE) are used which are defined as follows:

$$
\begin{aligned}
\mathrm{AE} & =\left|I_{\text {exi }}-I_{i}\right|, \\
\mathrm{RE} & =\frac{\left|I_{\mathrm{exi}}-I_{i}\right|}{I_{\text {exi }}} \times 100 \%, \\
\mathrm{RMSE} & =\sqrt{\frac{1}{n} \sum_{i=1}^{n}\left(I_{i}-I_{\mathrm{exi}}\right)^{2},}
\end{aligned}
$$

where $n$ is the number of experimental values. $I_{i}$ is the current of tested models. $I_{\text {exi }}$ is the current of experimental values.

To validate the effectiveness of the six-parameter model proposed in this paper, we compare the new six-parameter model with the five-parameter model in [14] and the sevenparameter model in [13]. We compute the parameter values by Engineering Equation Solver (EES) software. The parameter values of the six-parameter model in this paper, the fiveparameter model in [14], and the seven-parameter model [13] at SRC are shown in Table 2.

We extract the experimental data in [12] by the software called Get Data. GetData software can make every data point amplified 15 times the original size. Thus, we can control that the abscissa of data point (voltage) has an absolute error of less than $0.04 \mathrm{~V}$ and the ordinate of data point (current) has an absolute error of less than $0.006 \mathrm{~A}$. The experimental data obtained by GetData software has enough number of significant digit to achieve enough precision. Therefore, the experimental data obtained by GetData software can be taken as real experimental data provided in [14]. Then, we use the software Matlab to plot the figures of $I-V$ characteristic curves and the absolute errors between compared models

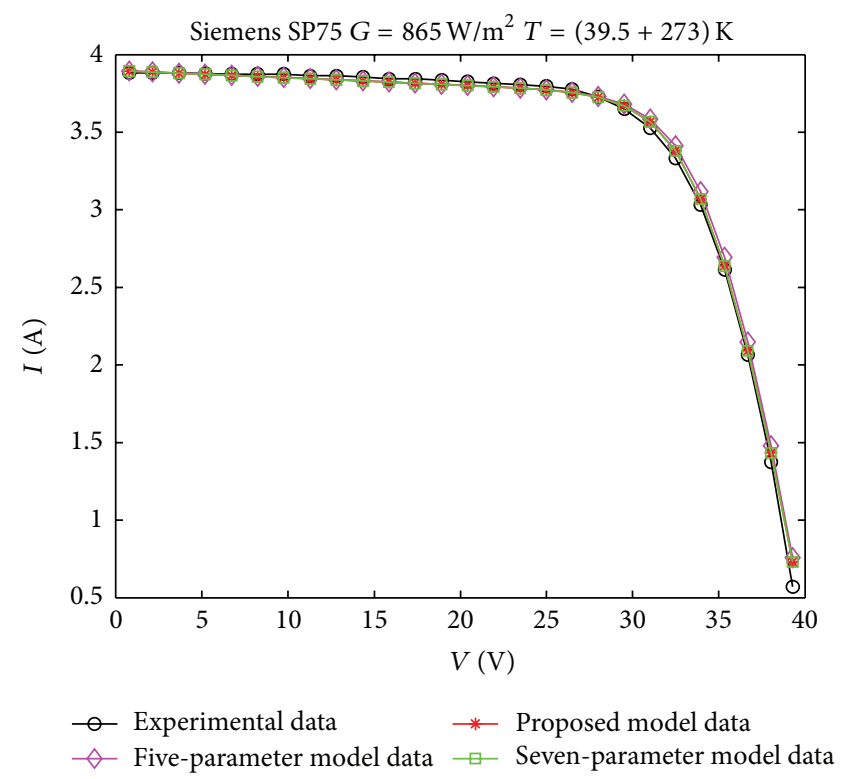

FIgURE 2: $I-V$ characteristic for SP75.

and experimental data. The $I-V$ characteristic curves of SP-75 module, MSX-64 module, and APX-90 module at different temperature and irradiance conditions are shown in Figures 2-4, Figures 5-7, and Figures 8-10, respectively. The corresponding absolute errors of $I-V$ characteristic curves for these three modules are shown in Figures 11-19. AEs of the six-parameter model in this paper is very close to the sevenparameter model in [13] at every point. For higher irradiance, the absolute errors of the six-parameter model in this paper are less than that of the five-parameter model in [14] within 
TABLE 3: RMSEs of different models for SP75, MSX-64, and APX-90 module.

\begin{tabular}{lccr}
\hline Module & & RMSE & \\
& Five-parameter model in [14] & Seven-parameter model in [13] & Six-parameter model \\
\hline SP75 & 0.06293749 & 0.056315982 & 0.056864662 \\
MSX-64 & 0.130276895 & 0.125862026 & 0.125859806 \\
APX-90 & 0.154802955 & 0.147627147 & 0.147625261 \\
\hline
\end{tabular}

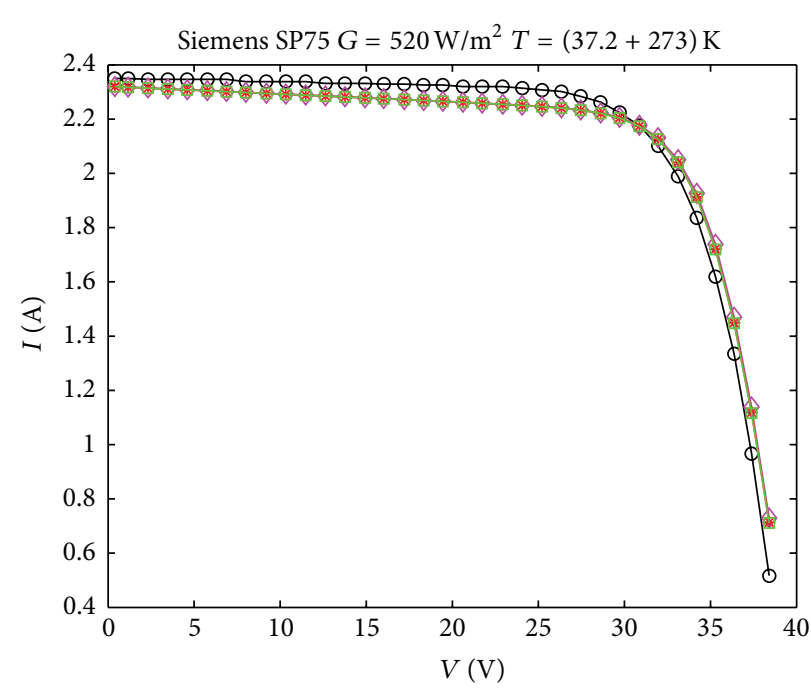

$\begin{array}{lll}\diamond-\text { Experimental data } & * & \text { Proposed model data } \\ \diamond & \text { Five-parameter model data } \rightarrow & \text { Seven-parameter model data }\end{array}$

FIGURE 3: $I-V$ characteristic for SP75.

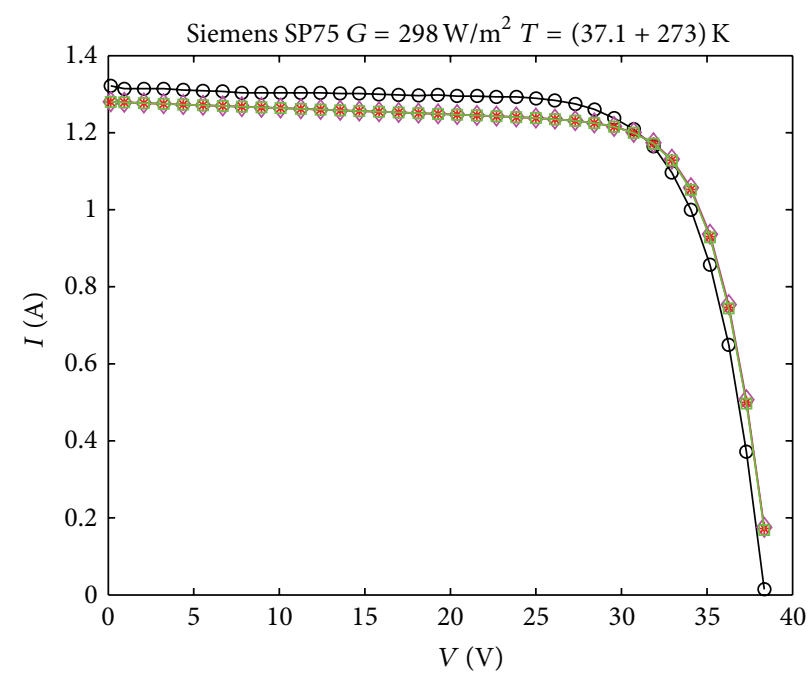

- Experimental data $\quad *$ Proposed model data

$\diamond$ Five-parameter model data $\square-$ Seven-parameter model data

FIGURE 4: $I-V$ characteristic for SP75.

the range of maximum-power point to open-circuit voltage point, shown in Figures 11-12, 14-15, and 17-18. For lower irradiance, AEs of the six-parameter model in this paper and the five-parameter model in [14] are almost the same. In addition, We use the maximum absolute error and RMSE to further analyze the effectiveness of the six-parameter model

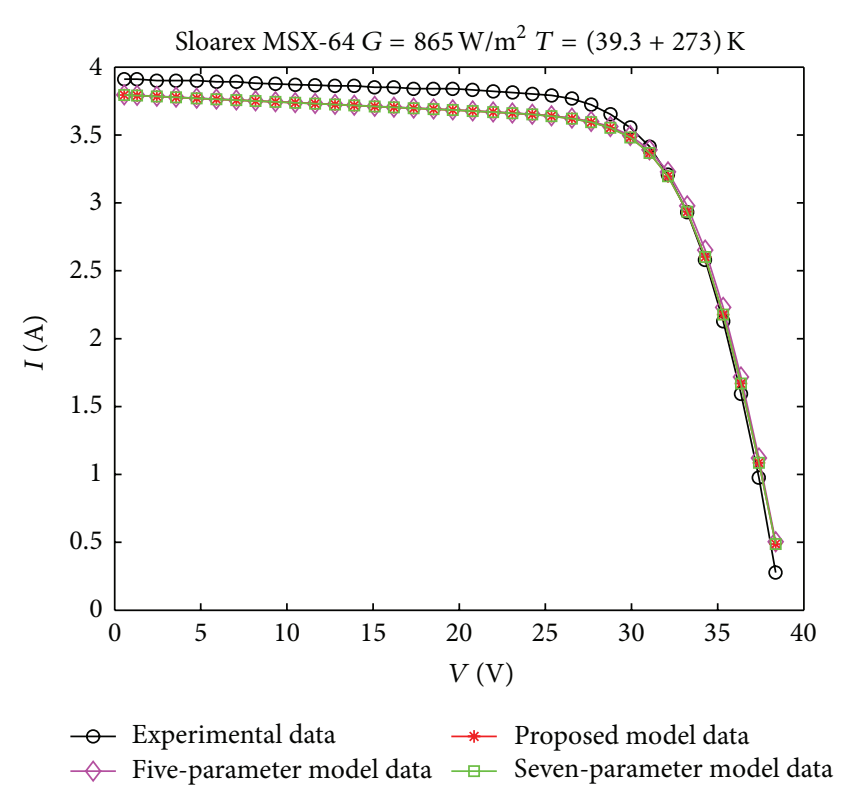

FIGURE 5: $I-V$ characteristic for MSX-64.

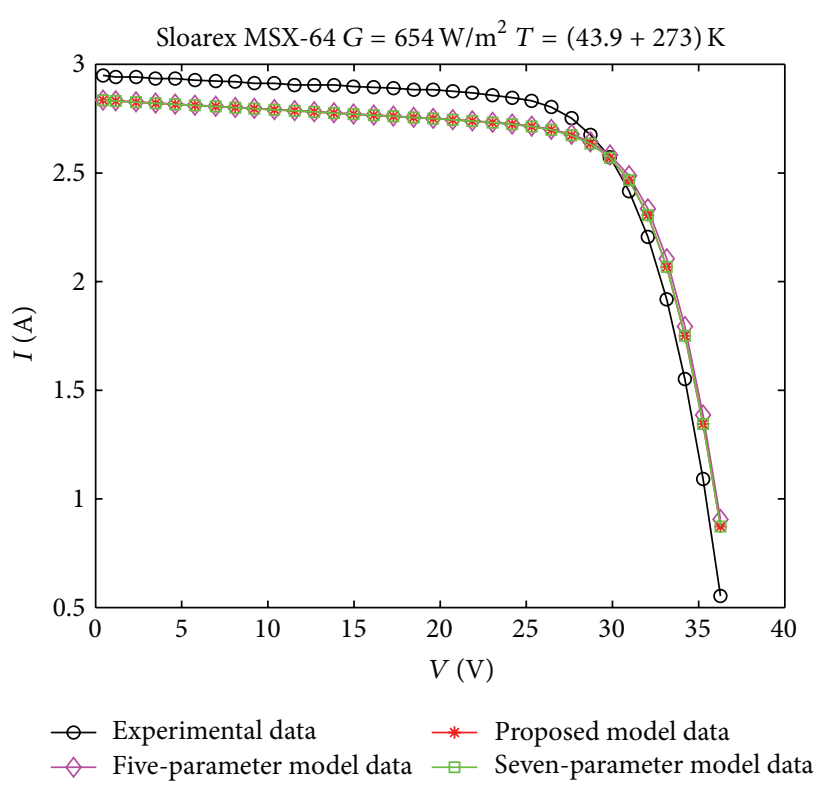

Figure 6: $I-V$ characteristic for MSX-64.

in this paper. RMSE shows overall error. We select 97 data sets for SP-75 module, 101 data sets for MSX-64 module and 108 data sets for APX-90 module to compute RMSEs, see Table 3. From Table 3, we can find that that RMSEs of the sixparameter model in this paper are almost the same as that of the seven-parameter model in [13] and are far less than that 


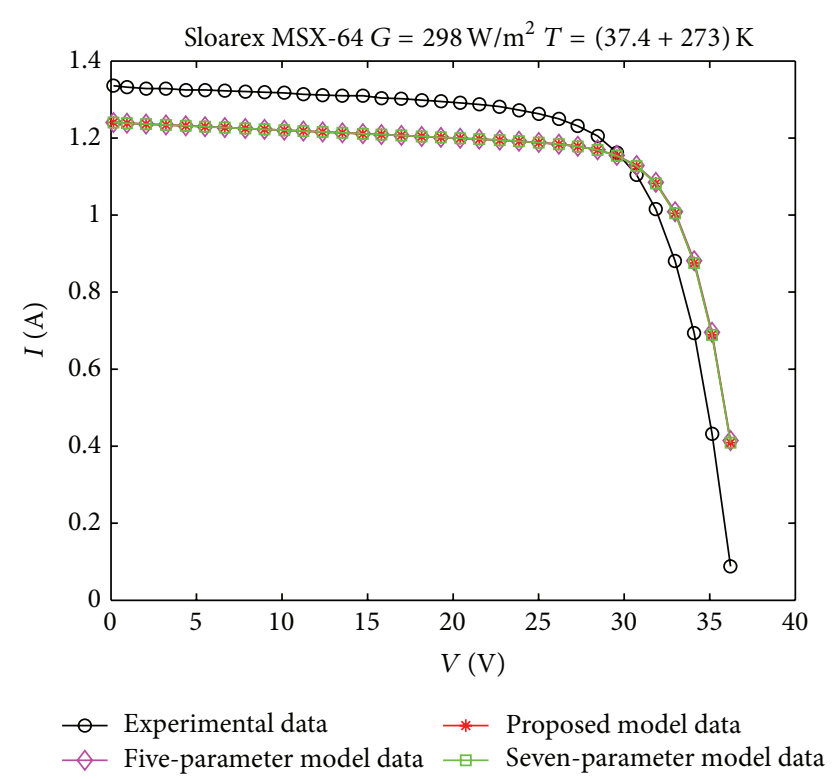

FIGURE 7: $I-V$ characteristic for MSX-64.

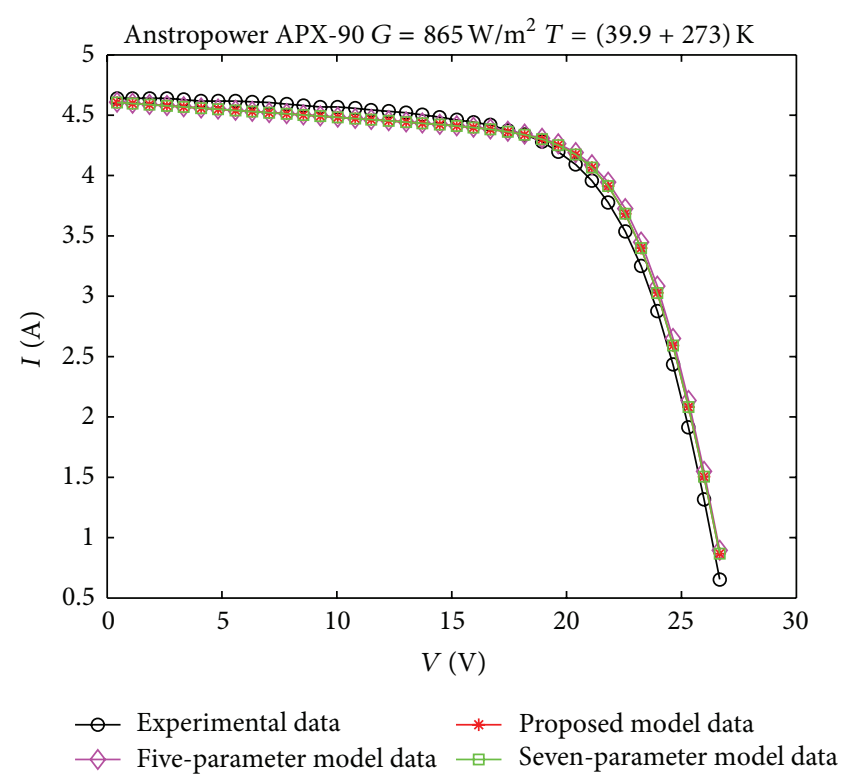

FIgURE 8: $I-V$ characteristic for APX-90.

of the five-parameter model in [14]. Therefore, in estimating of $I-V$ characteristic, the six-parameter model in this paper is obviously superior to the five-parameter model in [14], but slightly less than seven-parameter model in [13].

$I-V$ characteristic of $\mathrm{PV}$ modules are widely used to estimate the maximum power point. Next, we take the data of SM-55 module and US-21 module given in [32] as experimental data to validate the accuracy of the new sixparameter model in estimating the maximum power point. Tables 4 and 5 show $P_{\mathrm{mp}}$ and $V_{\mathrm{mp}}$ for the two PV modules at the temperature of $50^{\circ} \mathrm{C}$ and the irradiance of $1000 \mathrm{~W} / \mathrm{m}^{2}$ to $100 \mathrm{~W} / \mathrm{m}^{2}$. For SM-55 module and US- 21 module, the relative errors of the six-parameter model in this paper are almost the

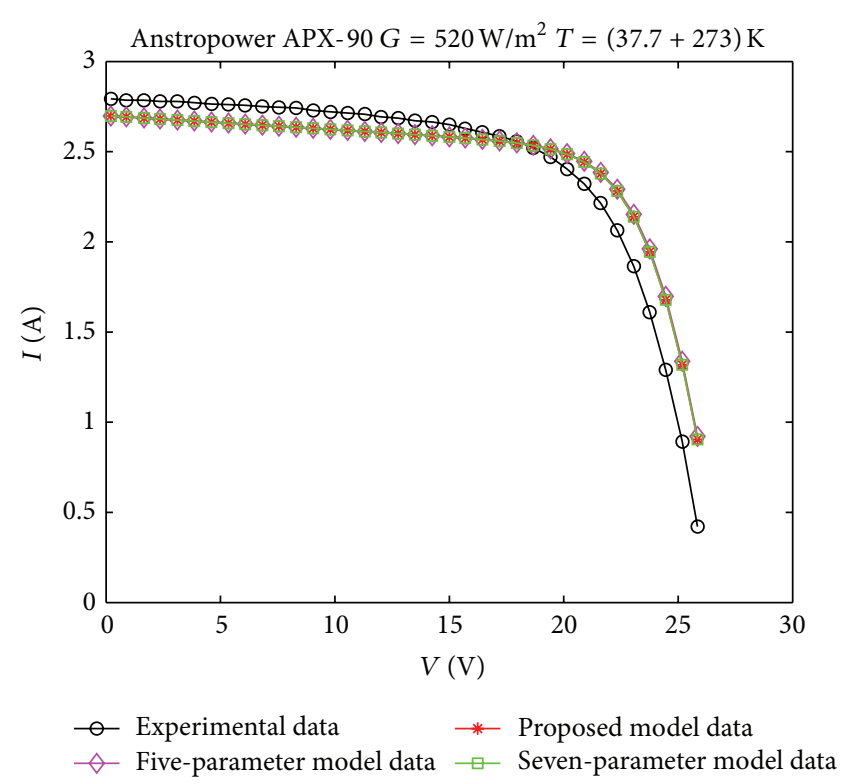

FIgURE 9: $I-V$ characteristic for APX-90.

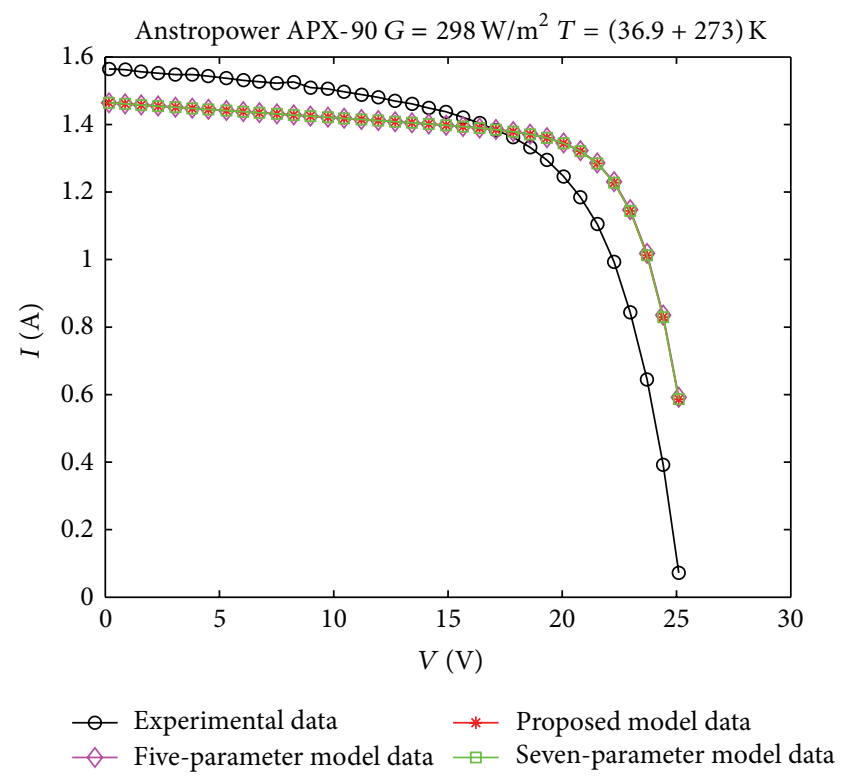

FIgURE 10: $I-V$ characteristic for APX-90.

same as that of the seven-parameter model in [13]. For SM-55 module, the relative errors of the six-parameter model in this paper are far less than that of five-parameter model in [14] except for irradiance of $1000 \mathrm{~W} / \mathrm{m}^{2}$ and $100 \mathrm{~W} / \mathrm{m}^{2}$. For US21 module, the relative errors of the six-parameter model in this paper are far less than that of five-parameter model in [14] except for irradiance of $1000 \mathrm{~W} / \mathrm{m}^{2}$. This shows that the sixparameter model in this paper can give a better estimation of maximum power point at lower irradiance for tripe-junction amorphous silicon module.

Therefore, the six-parameter model in this paper, used to estimate $I-V$ characteristic and the maximum power point, is obviously superior to the five-parameter model in 


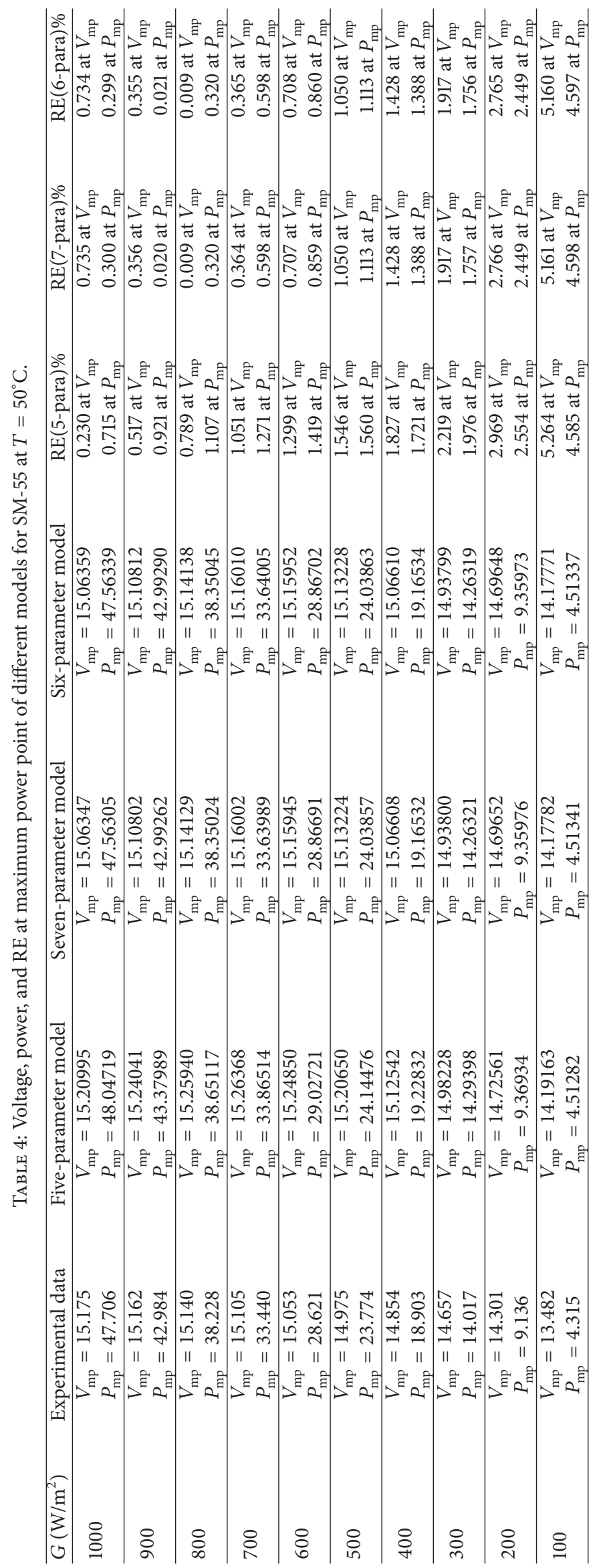




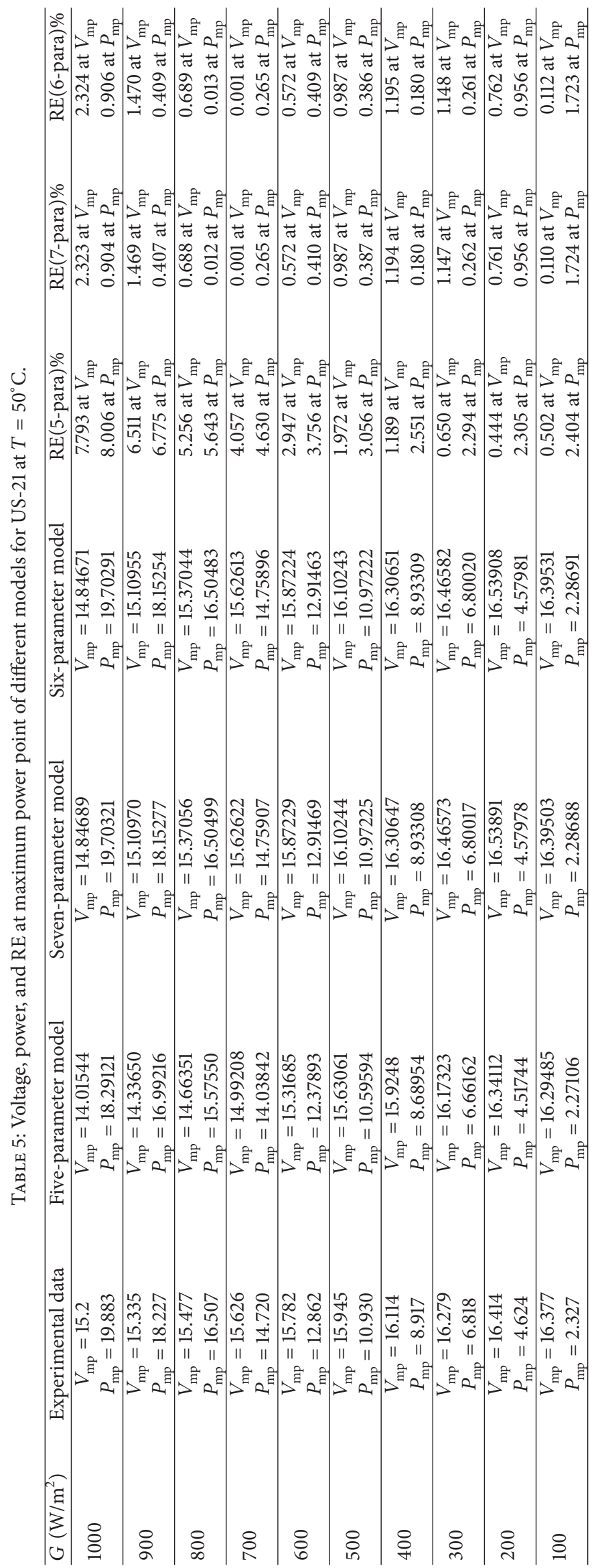




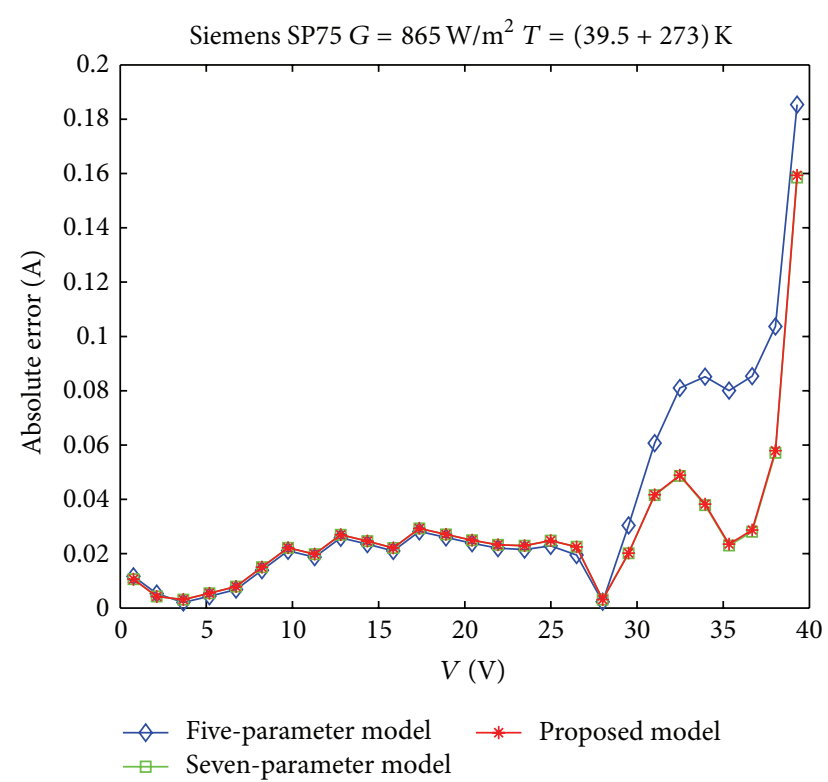

Figure 11: Absolute error for SP75.

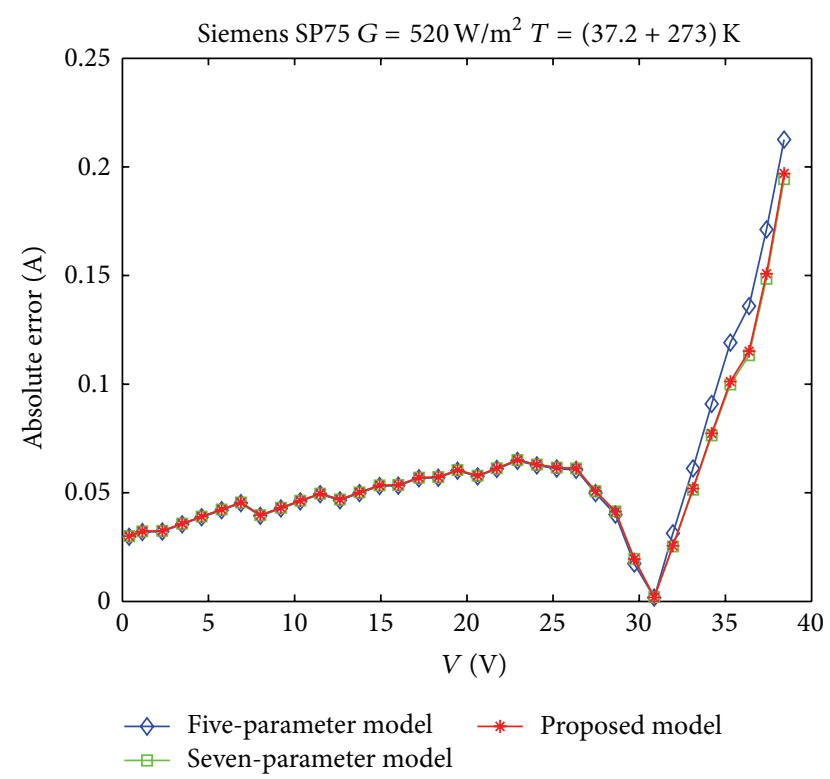

FIGURE 12: Absolute error for SP75.

[14] under most weather conditions, and is close to sevenparameter model in [13]. In fact, the six-parameter model in this paper makes a good compromise between the fiveparameter model in [14] and the seven-parameter model in [13] at accuracy and computational complexity. Therefore, the six-parameter model is an $I-V$ model with moderate computational complexity and high precision.

\section{Conclusions}

We propose a new six-parameter model for solar cells in this paper. At calculation accuracy, the six-parameter model is better than the five-parameter model. The prediction of

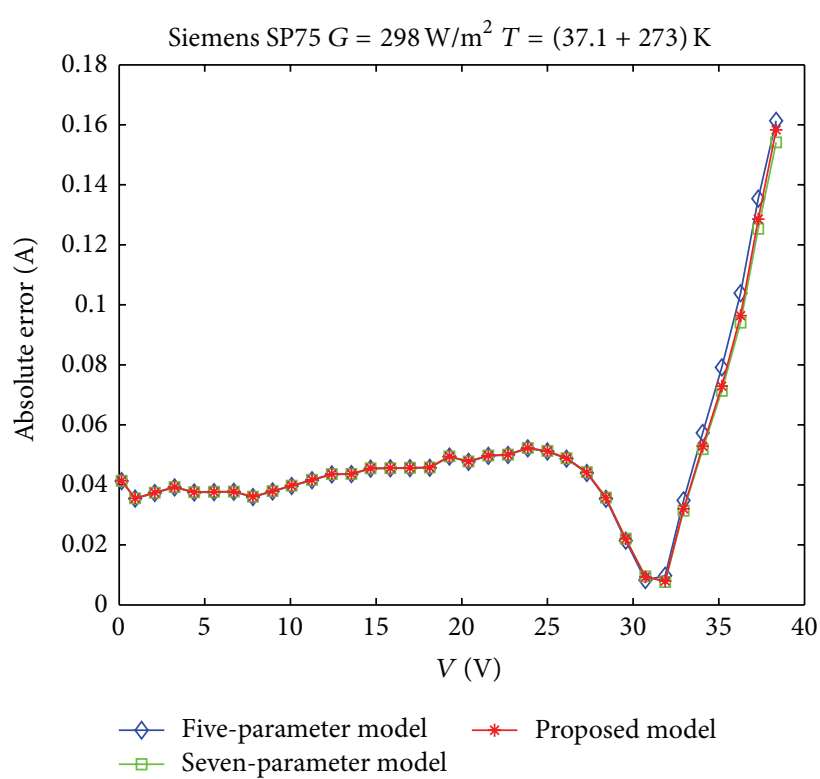

FIGURE 13: Absolute error for SP75.

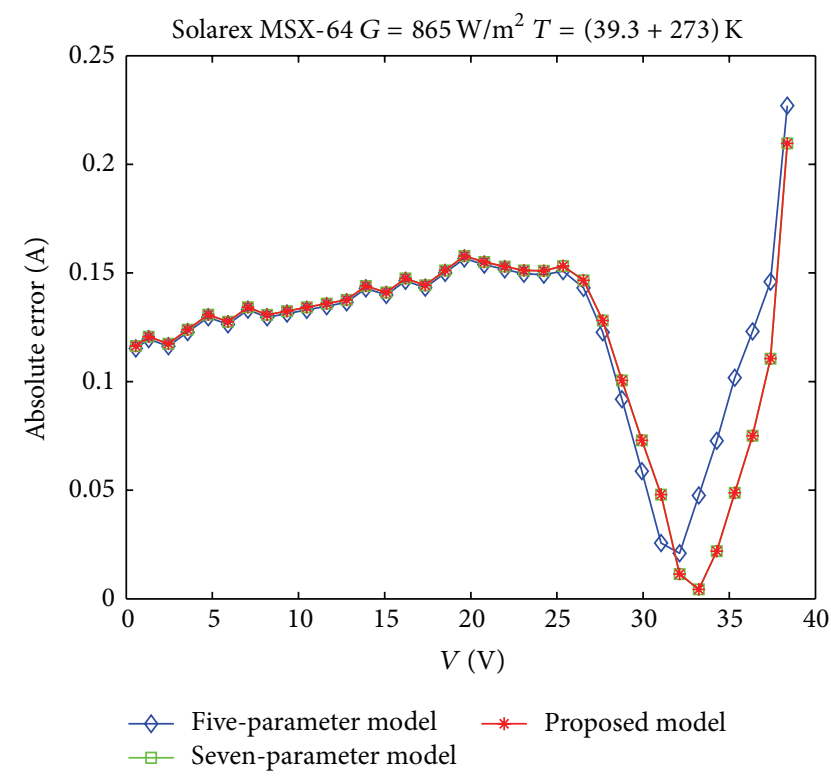

FIgURE 14: Absolute error for MSX-64.

$I-V$ characteristic of six-parameter model is very close to the seven-parameter model, but less than seven-parameter model. However, at the computational complexity, the sixparameter model is superior to the seven-parameter model. Experiment results show that the new six-parameter model can provide a good prediction for silicon solar cells with different technology types, that is, monocrystalline silicon, polycrystalline silicon, thin film silicon, and tripe-junction amorphous silicon. That is to say, the model in this paper is more universal. It is worth mentioning that the relationship between the series resistance and temperature is described by using Chebyshev polynomials in this paper. Therefore, the six-parameter model proposed in this paper is an $I-V$ model with moderate computational complexity and high precision. 


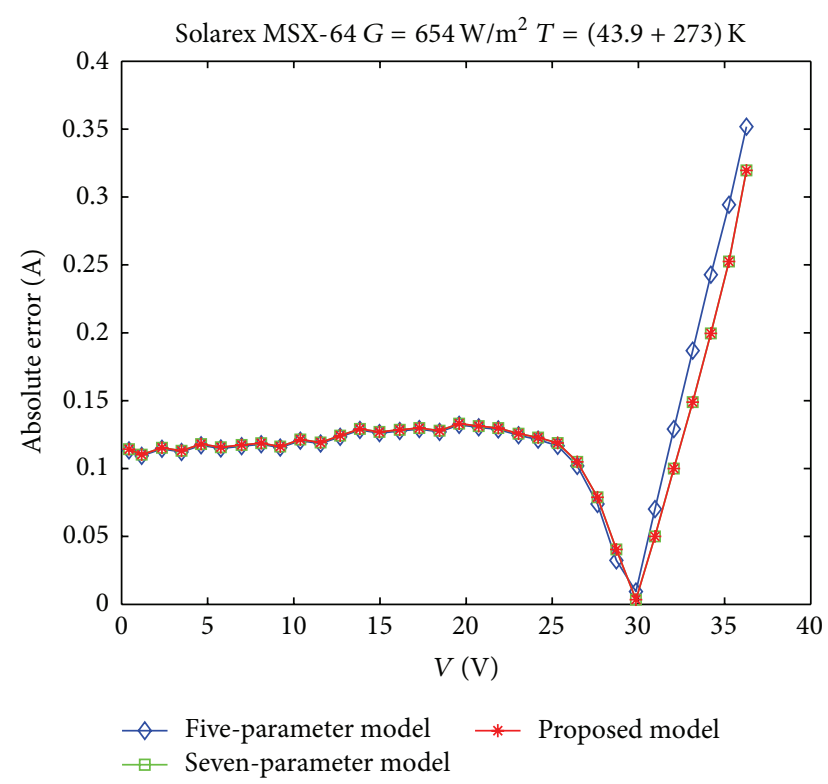

Figure 15: Absolute error for MSX-64.

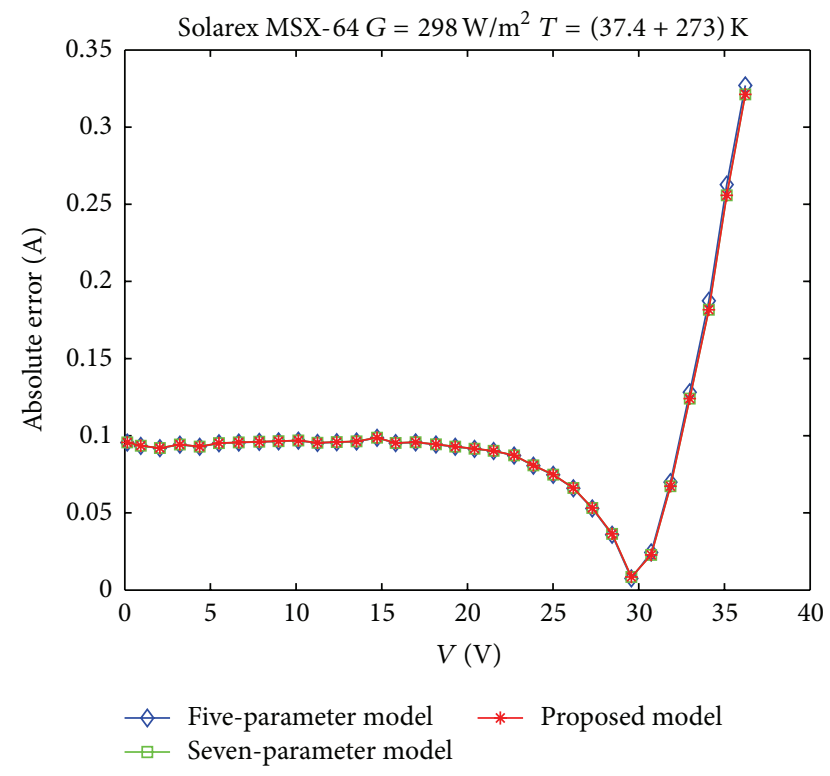

FIgURE 16: Absolute error for MSX-64.

\section{Nomenclature}

a: Ideality factor parameter which is defined as $a \equiv N_{s} n_{I} V_{t}$

$a_{\text {ref }}$ : Ideality factor parameter at SRC

$E_{g}: \quad$ Energy bandgap (eV)

$E_{g, \text { ref }}$ : Energy bandgap at SRC $(\mathrm{eV})$

$G: \quad$ Solar irradiance $\left(\mathrm{W} / \mathrm{m}^{2}\right)$

$G_{\text {ref }}:$ Solar irradiance at SRC $\left(\mathrm{W} / \mathrm{m}^{2}\right)$

I: $\quad$ Current (A)

$I_{L}: \quad$ Light-generated current (A)

$I_{L, \text { ref }}$ : Light-generated current at SRC (A)

$I_{\mathrm{mp}}$ : The current at maximum power point (A)

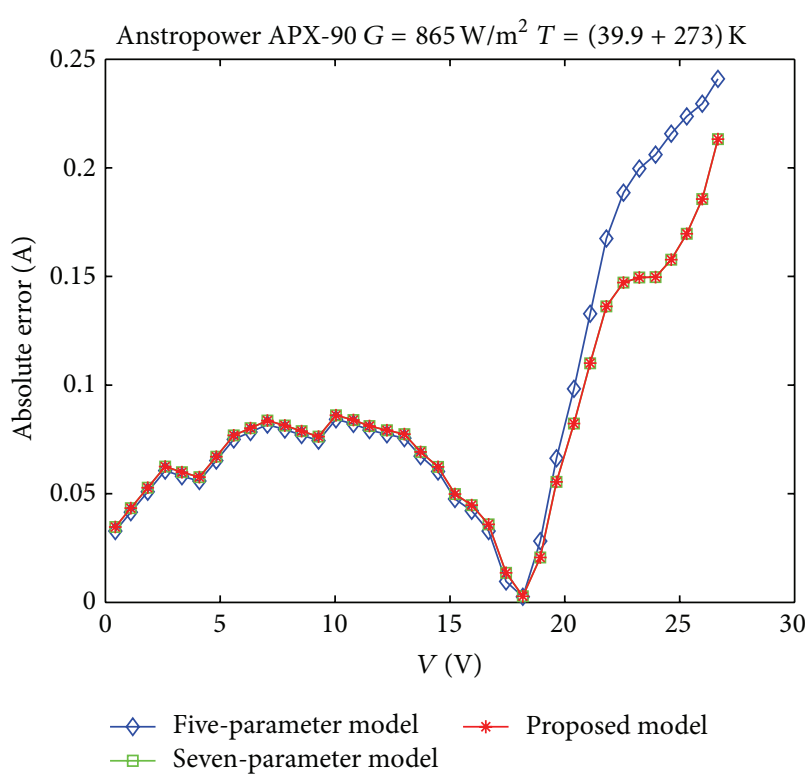

FIgURE 17: Absolute error for APX-90.

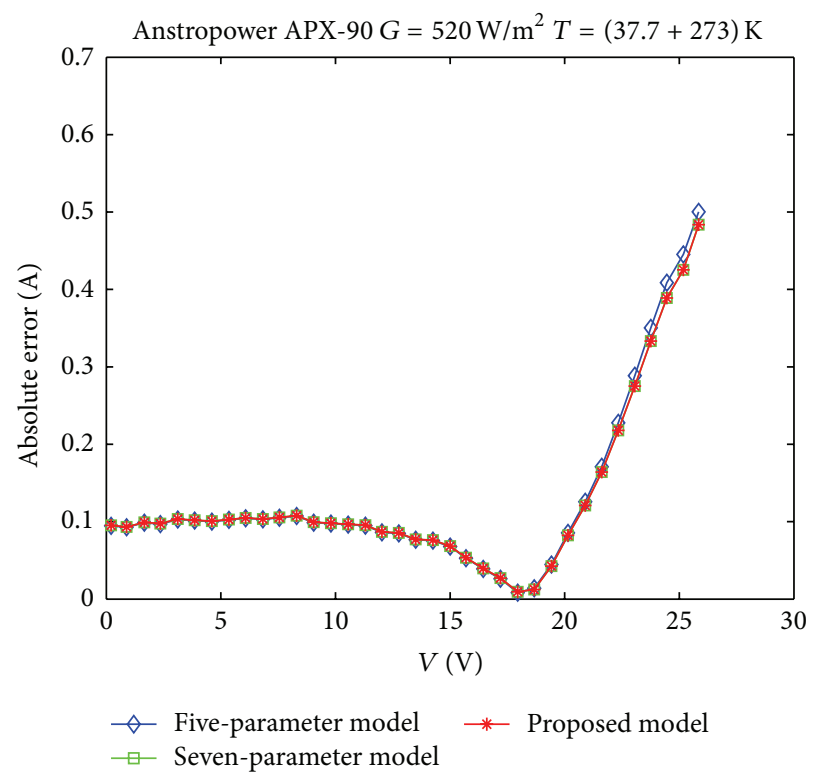

Figure 18: Absolute error for APX-90.

$I_{\mathrm{mp}, \mathrm{ref}}$ : The current at maximum power point at SRC

(A)

$I_{o}: \quad$ Diode reverse saturation current (A)

$I_{o \text {,ref }}$ : Diode reverse saturation current at SRC (A)

$I_{\text {sc }}: \quad$ Short-circuit current (A)

$I_{\text {sc,ref }}$ : Short-circuit current at SRC (A)

$k: \quad$ Boltzmann's constant $(1.38066 E-23 \mathrm{~J} / \mathrm{K})$

$n_{I}: \quad$ Diode ideality factor

$N_{s}$ : Number of solar cells in series in one module

$P_{\mathrm{mp}}$ : $\quad$ Power at maximum power point (W)

$P_{\mathrm{mp}, \mathrm{ref}}$ : Power at maximum power point at SRC (W)

$q$ : $\quad$ Electron charge $(1.60218 E-19 \mathrm{C})$ 


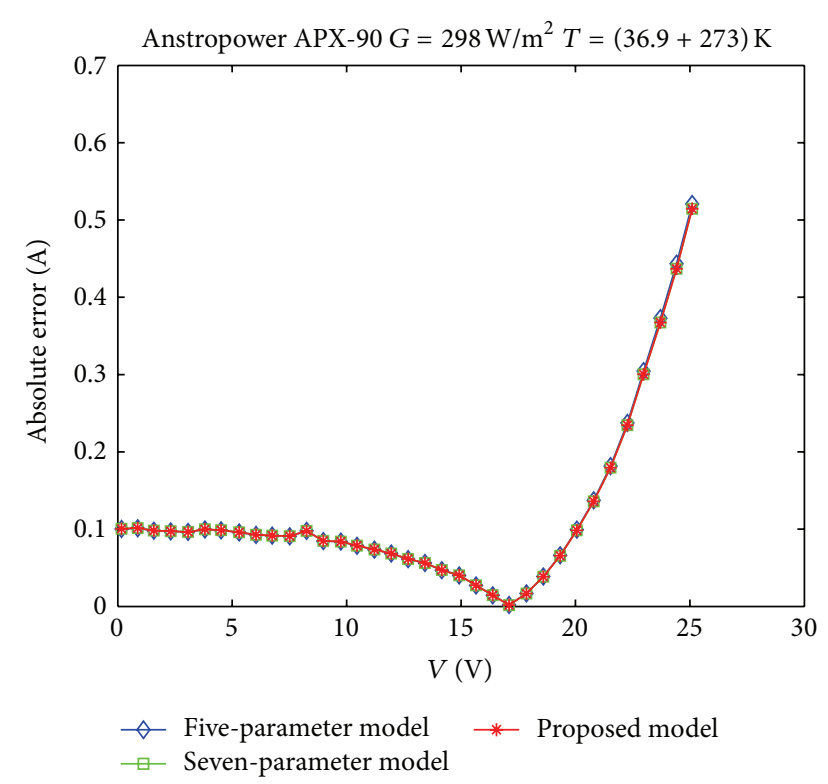

FIGURE 19: Absolute error for APX-90.

$\delta: \quad$ Temperature coefficient for series resistance

$R_{s}: \quad$ Series resistance $(\Omega)$

$R_{s, \text { ref }}$ : Series resistance at SRC $(\Omega)$

$R_{\text {sh }}$ : Shunt resistance $(\Omega)$

$R_{\text {sh,ref }}$ : Shunt resistance at $\operatorname{SRC}(\Omega)$

$T: \quad$ Cell temperature (K)

$T_{\text {ref }}: \quad$ Cell temperature at SRC $(\mathrm{K})$

$V: \quad$ Voltage $(\mathrm{V})$

$V_{\mathrm{mp}}$ : The voltage at maximum power point (V)

$V_{\text {mp,ref }}$ : The voltage at maximum power point at SRC (V)

$V_{\text {oc }}: \quad$ Open-circuit voltage $(\mathrm{V})$

$V_{\text {oc,ref }}$ : Open-circuit voltage at SRC (V)

$V_{t}: \quad$ Thermal voltage $(\mathrm{V})$

$\alpha_{I_{\text {mp }}}: \quad$ Temperature coefficient for maximum power current $(\mathrm{A} / \mathrm{K})$

$\alpha_{I_{\mathrm{sc}}}: \quad$ Temperature coefficient for short-circuit current $(\mathrm{A} / \mathrm{K})$

$\beta_{V_{\mathrm{mp}}}$ : Temperature coefficient for maximum power voltage $(\mathrm{V} / \mathrm{K})$

$\beta_{V_{\mathrm{oc}}}$ : Temperature coefficient for open-circuit voltage $(\mathrm{V} / \mathrm{K})$

$\gamma_{P_{\text {mp }}}: \quad$ Temperature coefficient for maximum power $(1 / \mathrm{K})$

$\Delta_{T}: \quad$ Temperature changing factor.

\section{Conflict of Interests}

The authors declare that there is no conflict of interests regarding the publication of this paper.

\section{Acknowledgments}

This work was supported by the Program for New Century Excellent Talents in University under Grant NCET-11-1005, the Nature Science Foundation of Liaoning Province under Grants 201102005 and 201402014, the First Batch of Science and Technology Projects of Liaoning Province under Grant 2011402001, and Liaoning BaiQianWan Talents Program under Grant 2012921061.

\section{References}

[1] H. G. Zhang, T. D. Ma, and G.-B. Huang, "Robust global exponential synchronization of uncertain chaotic delayed neural networks via dual-stage impulsive control," IEEE Transactions on Systems, Man, and Cybernetics. Part B: Cybernetics, vol. 40, no. 3, pp. 831-844, 2010.

[2] H. G. Zhang, B. Jiang, and W. Yu, "Data-driven fault supervisory control theory and applications," Mathematical Problems in Engineering, vol. 2013, Article ID 387341, 2 pages, 2013.

[3] H. G. Zhang, C. B. Qin, B. Jiang, and Y. H. Luo, "Online adaptive policy learning algorithm for $H_{\infty}$ state feedback control of unknown affine nonliear discretetime systems," IEEE Transactions on Cybernetics, vol. 44, no. 12, pp. 2706-2718, 2014.

[4] H. G. Zhang, Q. Wang, E. H. Chu, X. Liu, and L. Hou, "Analysis and implementation of a passive lossless soft-switching snubber for PWM inverters," IEEE Transactions on Power Electronics, vol. 26, no. 2, pp. 411-426, 2011.

[5] Q. Wang, H.-G. Zhang, E.-H. Chu, X.-C. Liu, and L.-M. Hou, "A novel three-phase passive soft-switching inverter," Proceedings of the Chinese Society of Electrical Engineering, vol. 29, no. 18, pp. 33-40, 2009.

[6] H.-G. Zhang, Q. Wang, E.-H. Chu, L.-M. Hou, and C. Chen, "A novel resonant DC link soft-switching inverter," Proceedings of the Chinese Society of Electrical Engineering, vol. 30, no. 3, pp. 21-27, 2010.

[7] S.-X. Lun, C.-J. Du, T.-T. Guo, S. Wang, J.-S. Sang, and J.-P. Li, "A new explicit $I-V$ model of a solar cell based on taylor's series expansion," Solar Energy, vol. 94, pp. 221-232, 2013.

[8] K. M. El-Naggar, M. R. AlRashidi, M. F. AlHajri, and A. K. Al-Othman, "Simulated Annealing algorithm for photovoltaic parameters identification," Solar Energy, vol. 86, no. 1, pp. 266274, 2012.

[9] S. X. Lun, C. J. Du, G. H. Yang et al., "An explicit approximate $I-V$ characteristic model of a solar cell based on padé approximants," Solar Energy, vol. 92, pp. 147-159, 2013.

[10] A. Askarzadeh and A. Rezazadeh, "Parameter identification for solar cell models using harmony search-based algorithms," Solar Energy, vol. 86, no. 11, pp. 3241-3249, 2012.

[11] A. N. Celik and N. Acikgoz, "Modelling and experimental verification of the operating current of mono-crystalline photovoltaic modules using four- and five-parameter models," Applied Energy, vol. 84, no. 1, pp. 1-15, 2007.

[12] W. de Soto, S. A. Klein, and W. A. Beckman, "Improvement and validation of a model for photovoltaic array performance," Solar Energy, vol. 80, no. 1, pp. 78-88, 2006.

[13] T. Boyd, Evaluation and validation of equivalent circuit photovoltaic solar cell performance models [M.S. thesis], Mechanical Engineering, Univerisity of Wisconsin-Madison, 2010.

[14] W. De Soto, Improved approximate analytical solution for generalized diode equation [M.S. thesis], Mechanical Engineering, University of Wisconsin-Madison, 2004.

[15] J. M. Ma, T. O. Ting, K. L. Man, N. Zhang, S.-U. Guan, and P. W. Wong, "Parameter estimation of photovoltaic models 
via cuckoo search," Journal of Applied Mathematics, vol. 2013, Article ID 362619, 8 pages, 2013.

[16] J. Appelbaum and A. Peled, "Parameters extraction of solar cells-a comparative examination of three methods," Solar Energy Materials \& Solar Cells, vol. 122, pp. 164-173, 2014.

[17] C. Wen, C. Fu, J. L. Tang, D. X. Liu, S. F. Hu, and Z. G. Xing, "The influence of environment temperatures on single crystalline and polycrystalline silicon solar cell performance," Science China: Physics, Mechanics and Astronomy, vol. 55, no. 2, pp. 235-241, 2012.

[18] M. Lal and S. N. Singh, "A new method of determination of series and shunt resistances of silicon solar cells," Solar Energy Materials and Solar Cells, vol. 91, no. 2-3, pp. 137-142, 2007.

[19] M. A. de Blas, J. L. Torres, E. Prieto, and A. García, "Selecting a suitable model for characterizing photovoltaic devices," Renewable Energy, vol. 25, no. 3, pp. 371-380, 2002.

[20] D. T. Cotfas, P. A. Cotfas, and S. Kaplanis, "Methods to determine the dc parameters of solar cells: a critical review," Renewable and Sustainable Energy Reviews, vol. 28, pp. 588-596, 2013.

[21] P. Singh, S. N. Singh, M. Lal, and M. Husain, “Temperature dependence of $I-V$ characteristics and performance parameters of silicon solar cell," Solar Energy Materials and Solar Cells, vol. 92, no. 12, pp. 1611-1616, 2008.

[22] M. Sheraz Khalid and M. Abido, "A novel and accurate photovoltaic simulator based on seven-parameter model," Electric Power Systems Research, vol. 116, pp. 243-251, 2014.

[23] A. Tataroğlu and Ş. Altindal, "The analysis of the series resistance and interface states of MIS Schottky diodes at high temperatures using $I-V$ characteristics," Journal of Alloys and Compounds, vol. 484, no. 1-2, pp. 405-409, 2009.

[24] A. K. Das, "Analytical expression of the physical parameters of an illuminated solar cell using explicit J-V model," Renewable Energy, vol. 52, pp. 95-98, 2013.

[25] S. Daliento and L. Lancellotti, "3D Analysis of the performances degradation caused by series resistance in concentrator solar cells," Solar Energy, vol. 84, no. 1, pp. 44-50, 2010.

[26] Y. Li, W. X. Huang, H. Huang et al., "Evaluation of methods to extract parameters from current-voltage characteristics of solar cells," Solar Energy, vol. 90, pp. 51-57, 2013.

[27] J. L. Ding, X. F. Cheng, and T. R. Fu, "Analysis of series resistance and $P$-T characteristics of the solar cell," Vacuum, vol. 77, no. 2, pp. 163-167, 2005.

[28] E. Cuce, P. M. Cuce, and T. Bali, "An experimental analysis of illumination intensity and temperature dependency of photovoltaic cell parameters," Applied Energy, vol. 111, pp. 374-382, 2013.

[29] A. Redinger, M. Mousel, M. H. Wolter, N. Valle, and S. Siebentritt, "Influence of S/Se ratio on series resistance and on dominant recombination pathway in $\mathrm{Cu}_{2} \mathrm{ZnSn}(\mathrm{SSe})_{4}$ thin film solar cells," Thin Solid Films, vol. 535, no. 1, pp. 291-295, 2013.

[30] Y. Jin and Y. Chen, Numerical Method, China Machine Press, 2004.

[31] R. Burden and J. Faires, Numerical Analysis, Thomson Learning Press, 2003.

[32] E. Karatepe and T. Hiyama, "Polar coordinated fuzzy controller based real-time maximum-power point control of photovoltaic system," Renewable Energy, vol. 34, no. 12, pp. 2597-2606, 2009. 


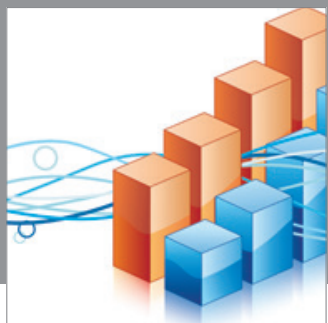

Advances in

Operations Research

mansans

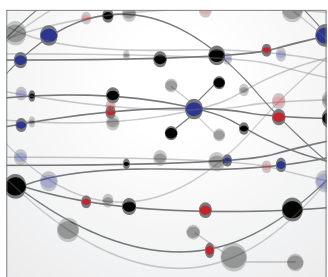

The Scientific World Journal
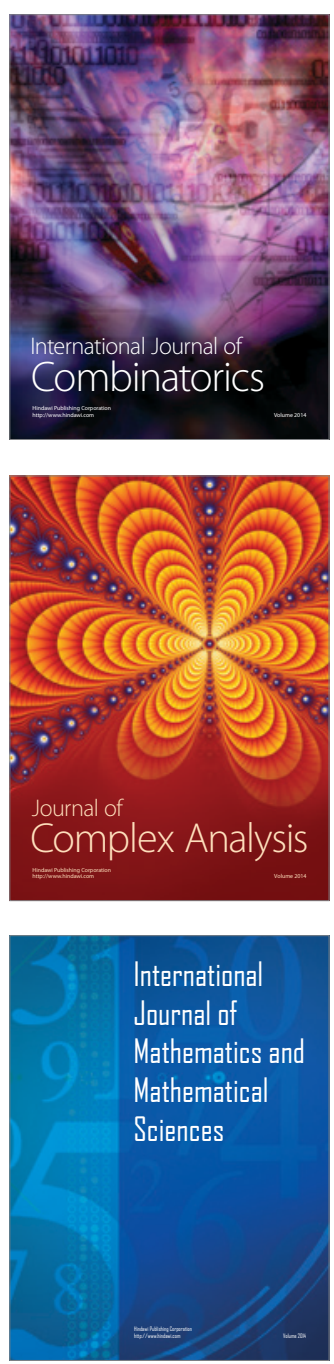
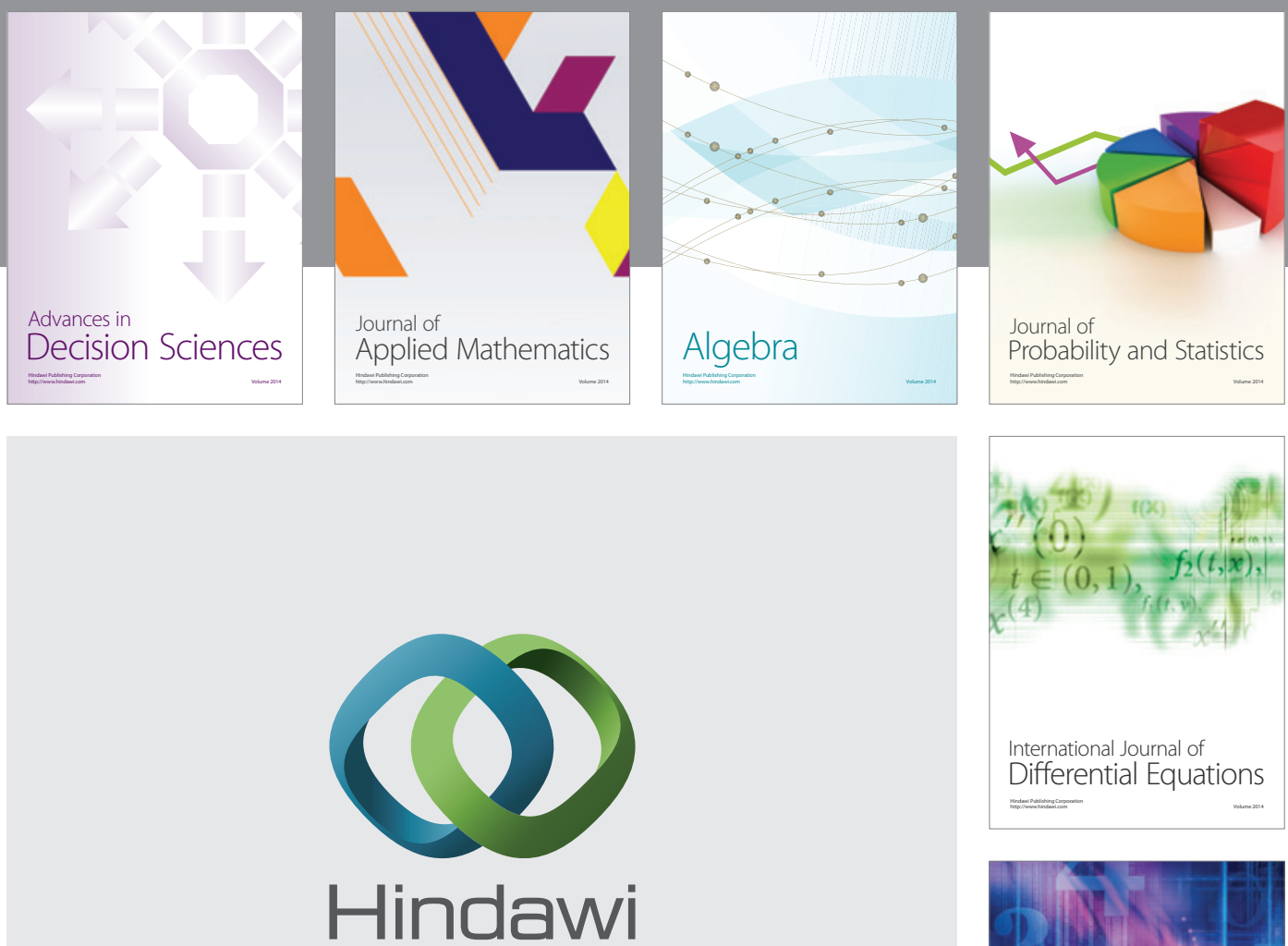

Submit your manuscripts at http://www.hindawi.com
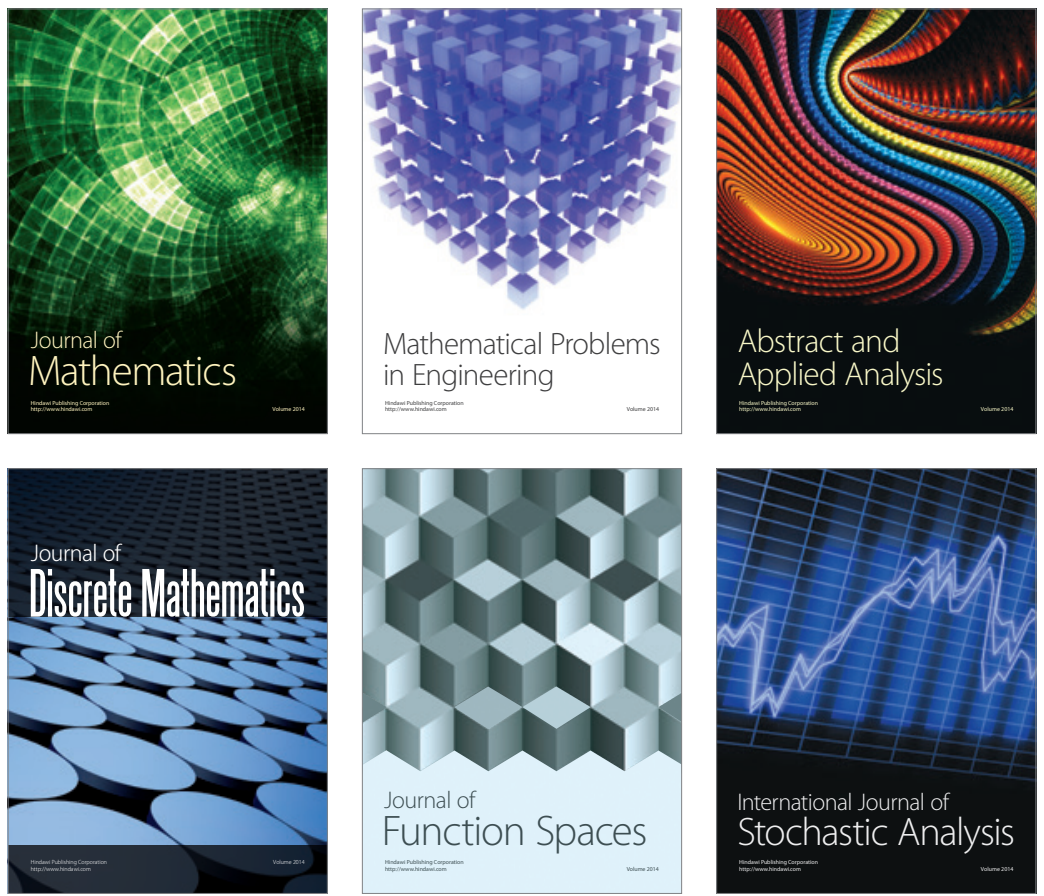

Journal of

Function Spaces

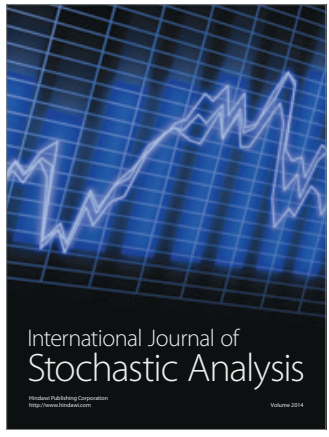

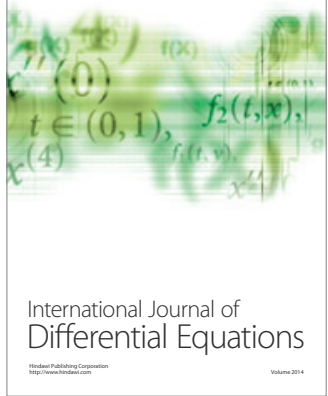
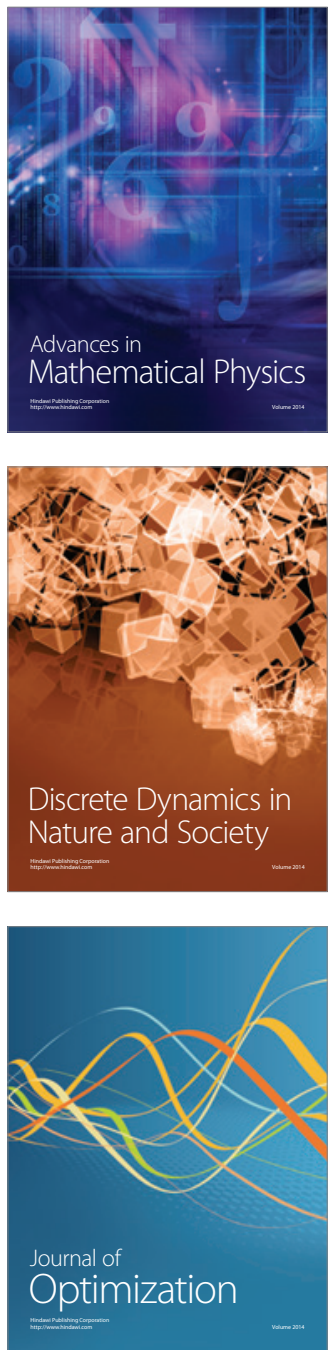